\title{
Effect of cerium oxide on erythrocyte deformability in rat lower extremity ischemia reperfusion injury
}

\author{
Tatar $\mathrm{T}^{1}$, Polat $\mathrm{Y}^{2 *}$, Comu $\mathrm{FM}^{3}$, Kartal $\mathrm{H}^{4}$, Arslan $\mathrm{M}^{5}$, Kucuk $\mathrm{A}^{6}$ \\ Gazi University Medical Faculty, Department of Anesthesiology and Reanimation, Ankara, Turkey. \\ mustarslan@gmail.com
}

\begin{abstract}
BACKGROUND: Cerium oxide is the oxide form of cerium, which has protective effects in ischemia reperfusion $(\mathrm{I} / \mathrm{R})$ injury. The purpose of our study was to look into the effects of this rare-earth metal on erythrocyte deformability in rat lower extremity I/R injury model.

MATERIALS AND METHODS: We used 24 Wistar albino rats as subjects in our study. They were divided into 4 groups; randomized control group (group $\mathrm{C} ; \mathrm{n}=6$ ), cerium oxide group $0.5 \mathrm{mg} \cdot \mathrm{kg}^{-1}$, intraperitoneal (group CO; $\mathrm{n}=$ 6), I/R group (group I/R; $\mathrm{n}=6$ ) and I/R group with cerium oxide $0.5 \mathrm{mg} \cdot \mathrm{kg}^{-1}$ intraperitoneally (group I/R-CO; $\mathrm{n}=6$ ). Erythrocyte packs were prepared from heparinized blood samples and deformability measurements were performed. RESULTS: We obtained similar results from the control and I/R-CO groups $(p=0.158)$. The results in I/R group were evidently higher than those of the control, CO, and IR-CO groups ( $<<0.0001, p<0.0001, p=0.001$, respectively). CONCLUSION: We detected unfavorable effects of I/R on erythrocyte deformability, which may impair blood flow and hence tissue perfusion in infrarenal rat aorta. We also found that cerium oxide had beneficial effects by reversing undesirable effects of I/R. Further studies with larger volume are required to support our promising results (Fig. 1, Ref. 24). Text in PDF www.elis.sk.

KEY WORDS: erythrocyte deformability, ischemia reperfusion, cerium oxide, rat.
\end{abstract}

\section{Introduction}

Ischemia reperfusion injury $(\mathrm{I} / \mathrm{R})$ is a notorious clinical phenomenon. Reperfusion of the ischemic tissue paradoxically causes local edema and muscle tissue necrosis. It is then followed by systemic inflammatory response syndrome and multiple organ failure (kidney, respiratory and circulatory systems etc.), which leads to an increased rate of mortality and morbidity (1-3).

Main features of reperfusion injury are cell swelling, degeneration of cell skeleton structure and loss of selective permeability at the cell membrane. These changes all result in a reduced capillary blood flow accompanied by tissue edema (4).

Cerium oxide $\left(\mathrm{CeO}_{2}\right)$, which is an oxide of a rare-earth metal called cerium, is an important nanomaterial. It has a wide range of applications such as: solar cells, fuel cells, gas sensors, oxygen pumps, and also used as a fuel additive (5).

${ }^{1}$ Department of Cardiovascular Surgery, Gazi University Medical Faculty, Ankara, Turkey, ${ }^{2}$ Department of Cardiovascular Surgery, Mehmet Akif Ersoy Thoracic and Cardiovascular Surgery Training and Research Hospital, Ankara, Turkey, ${ }^{3}$ Department of Physiology, Kirıkale University Medical Faculty, Kırıkkale, Turkey, ${ }^{4}$ Department of Cardiovascular Surgery, Ardahan State Hospital, Ardahan, Turkey, ${ }^{5}$ Department of Anaesthesiology and Reanimation, Gazi University Medical Faculty, Ankara, Turkey, and ${ }^{6}$ Department of Physiology, Dumlupinar University Medical Faculty, Kütahya, Turkey

Address for correspondence: M. Arslan, Dr, Gazi University Medical Faculty, Department of Anesthesiology and Reanimation, 06510 Ankara, Turkey.

Phone: +90.533 .4228577$

*These authors contributed equally to this work
This rare-earth metal has been listed as one of five nanomaterials under investigation by the U.S. Environmental Protection Agency. There is also growing interest in the medical field due to its potential antioxidant capabilities $(6,7)$. Nonetheless, few studies examined in vitro and in vivo inflammatory effects associated with $\mathrm{CeO}_{2}$, and especially, how it might alter systemic inflammatory responses (8).

Potential use of $\mathrm{CeO}_{2}$ nanoparticles to treat cardiomyopathy (7), stroke (9), ovarian cancer (10), sepsis (11), obesity (12, hepatic I/R (13), and intestinal I/R was investigated in several studies (14). However, it is still unknown if $\mathrm{CeO}_{2}$ nanoparticles can be used to attenuate erythrocyte deformability caused by I/R. Our study aimed to look into the potential effect of $\mathrm{CeO}_{2}$ on lower extremity muscle ischemia and subsequent I/R injury, which is provoked with the tourniquet method.

\section{Materials and methods}

\section{Animals and experimental protocol}

This study was conducted in the Physiology Laboratory of Kirikkale University upon the consent of Experimental Animals Ethics Committee of Gazi University. All the procedures were performed according to accepted standards of Guide for the Care and Use of Laboratory Animals.

The subjects in our study were 24 Wistar Albino rats weighing between 200 and $250 \mathrm{~g}$, which were nurtured under the same habitat. The subjects were kept under $20-21{ }^{\circ} \mathrm{C}$ within cycles of 12-hour daylight and 12-hour darkness. They were given free access to nutrition until 2 hours before the anesthesia procedure and 
$441-443$

randomly separated into four equal groups of 6 animals. Ketamine anesthesia was applied prior to midline laparotomy.

Control group (Group C): Midline laparotomy was the sole surgical procedure without any additional intervention. After 4 hours of follow-up, blood sample was collected and subjects were sacrificed.

Cerium oxide group (Group CO): Similarly, midline laparotomy was the sole surgical procedure without any additional intervention. Cerium oxide $0.5 \mathrm{mg} \cdot \mathrm{kg}^{-1}$ was administered intraperitoneally and again after 4 hours of follow-up, blood sample was collected and subjects were sacrificed.

Ischemia-reperfusion group (Group I/R): Midline laparotomy was done in a similar fashion. Infrarenal aorta was left clamped for 2 hours. After removing the clamp, reperfusion was established for another additonal 2 hours. At the end of 4 hours, blood samples were collected from the abdominal aorta and subjects were sacrificed.

Ischemia-reperfusion group with cerium oxide (Group I/R$C O)$ : After following the same steps in $\mathrm{I} / \mathrm{R}$ group, cerium oxide was given $\left(0.5 \mathrm{mg} \cdot \mathrm{kg}^{-1}\right)$ intraperitoneally 30 minutes before the ischemia period. At the end of 4 hours, blood samples were collected from the abdominal aorta and subjects were sacrificed.

Intraabdominal blood samples were collected after ketamine (100 mg.kg-1) was given intraperitoneally to all of the subjects. Erythrocyte packs were prepared with heparinized total blood samples. Erythrocyte suspensions of $5 \%$ hematocrit with phosphate buffered saline (PBS) were used for deformability measurements.

\section{Deformability measurements}

First, the samples were centrifuged for ten minutes at $1000 \mathrm{rpm}$ and then serum and the buffy coat on erythrocytes were removed. Then, isotonic PBS buffer was added to the collapsing erythrocytes. This mixture of PBS and erythrocytes was centrifuged for another ten minutes at the same speed of $1000 \mathrm{rpm}$. Subsequently, liquid was removed from the upper surface. Finally, pure red cell packs were obtained from three consequent washing processes. PBS buffer was mixed with erythrocyte packs in order to obtain a value. And those mixed suspensions with $5 \%$ hematocrit were used for deformability measurement. These procedures were done at $22^{\circ} \mathrm{C}$.

Deformability measurement was done with the constant-current filtrometer system. Samples of $10 \mathrm{ml}$ erytrocytes suspension - PBS buffer were prepared for the measurement. There was a constant flow rate of $1.5 \mathrm{ml} / \mathrm{min}$ through an infusion pump. We used a $28 \mathrm{~mm}$ nucleoporin polycabonate filter. which has a pore diameter of $5 \mu \mathrm{m}$. A transducer detected the pressure changes during the erythroctes passage through the filter and the collected data was transferred to computer with MP 30 data equation system (Biopac Systems Inc, Commat, USA). The pressure of the system was calibrated before each measurement. Buffer $\left(\mathrm{P}_{\mathrm{T}}\right)$ and then erythrocytes $\left(\mathrm{P}_{\mathrm{E}}\right)$ were passed subsequently through from the filtration system and pressure changes were measured. The relative refractory period value (Rrel) was calculated by relating the pressure value of erythrocyte suspension to pressure value of buffer. Increase in Rrel as the deformability index was interpreted as adverse effect on erythrocyte deformability.

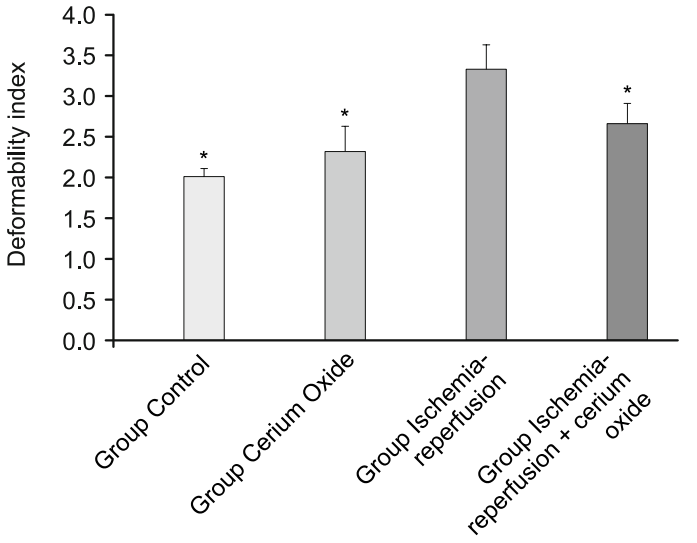

Fig. 1. Erythrocyte deformability index values of the groups. Each bar represents the mean $\pm \mathrm{SD} .{ }^{*} \mathbf{p}<\mathbf{0 . 0 5}$ compared to the Group I/R.

\section{Statistical analysis}

SPSS 17.0 software program was used for statistical analysis and $p<0.05$ was considered statistically significant. The findings were expressed as the mean \pm standard deviation. Kruskal-Wallis variance analysis was preferred for data evaluation. The variables with significance were evaluated with Bonferroni corrected Mann-Whitney U test.

\section{Results}

We found that the relative resistance, which is a marker of erythrocyte deformability, was significantly increased with IR, when compared to the control, CO, and I/R-CO groups ( $\mathrm{p}<0.05$ ) (Fig. 1).

Comparisons with Kruskal-Wallis test showed profound differences between the groups the $(\mathrm{p}<0.0001)$. After corrections with Bonferroni test, the following results were obtained: Comparisons of the control and I/R-CO groups showed similar results $(p=0.158)$. The obtained values of the $I / R$ group were significantly higher than those of the control, $\mathrm{CO}$, and I/R-CO groups ( $\mathrm{p}<0.0001, \mathrm{p}<0.0001, \mathrm{p}=0.001$, respectively).

\section{Discussion}

There are numerous studies showing a drastic increase in oxidative stress upon reperfusion $(15,16)$.

Several studies tested the efficacy of $\mathrm{CeO}_{2}$ nanoparticles in animal models of tissue damage. Intravenous injection of $\mathrm{CeO}_{2}$ nanoparticles has been shown to ameliorate intestinal injury following radiation induced damage in mice (17). In another study, intraperitoneal injection of $\mathrm{CeO}_{2}$ nanoparticles has been shown to attenuate acute kidney injury after systemic bacterial infection in rats (11). Although systemic administration of these nanoparticles in mice is well tolerated (18), there is evidence for potential toxicity effects of nanoceria. For example, aerosol delivery of $\mathrm{CeO}_{2}$ nanoparticles can promote pulmonary inflammation (19).

Gubernatorova et al (14) used mucosal administration of $\mathrm{CeO}_{2}$ nanoparticles, which effectively blocked superoxide accumulation in the intestine and ameliorated intestinal injury following I/R. 
It was shown that $\mathrm{CeO}_{2}$ nanoparticles remain in the circulation for a short period of time such as $\mathrm{t} 1 / 2$ of $7.5 \mathrm{~min}$. upon intravenous injection (20). It has been shown that oxidative stress drastically increases upon reperfusion $(15,16)$ and the administration of $\mathrm{CeO}_{2}$ nanoparticles one hour prior to ischemia would result in bioaccumulation of $\mathrm{CeO}_{2}$ nanoparticles in liver and scavenge ROS that have been generated during reperfusion.

Manne et al (13) showed that $\mathrm{CeO}_{2}$ nanoparticles decreased I/R induced cell death and suggested their use for prophylaxis against hepatic injury associated with graft failure. They concluded that $\mathrm{CeO}_{2}$ nanoparticles could be a novel therapeutic approach for hepatic I/R injury.

Erythrocytes are responsible for the delivery of oxygen and vital molecules to the final organ capillaries as well as of metabolic wastes. They must be able to extend and curve to move in the capillary level hence this capacity, termed as "deformability" is much more important in microcirculation. Decreased erythrocyte deformability alters the oxygen delivery capacity and also has a negative impact on the survival of the circulating erythrocytes(21-23).

In vitro $\mathrm{CeO}_{2}$ exposure leads to an increase in of PGD2, TNF-a, IL-6 and osteopontin production by cultured mast cells. In contrast to other studies, Wingart et $\mathrm{al}^{8}$ showed that $\mathrm{CeO}_{2}$ nanoparticles trigger mast cells and contribute to pulmonary inflammation, impairment of vascular relaxation and exacerbation of myocardial $\mathrm{I} / \mathrm{R}$ injury (Mast cells contribute to altered vascular reactivity and $\mathrm{I} / \mathrm{R}$ injury following $\mathrm{CeO}_{2}$ nanoparticle instillation).

Kotsuruba et al (24) used for 14 days per os in old rats 0.1 $\mathrm{mg} / \mathrm{kg}$ of nanocerium, which fully restored the resistance of erythrocytes to acid hemolysis by ROS and RNS in both plasma and erythrocytes reduction. Nanocerium decreased the erythrocytes and, conversely, significantly increased the plasma's pools of $\mathrm{H} 2 \mathrm{~S}$.

We think that measurement of erythrocyte deformability can be used as a parameter in cases of $\mathrm{I} / \mathrm{R}$ because its impairment leads to disturbance of microvascular perfusion and related problems. We were able to document the potential beneficial effect of cerium oxide on maintaining erythrocyte deformability after I/R, but we still think these promising results should further be supported by more detailed studies with larger volumes.

\section{References}

1. Duru S, Koca U, Oztekin S, Olguner C, Kar A, Coker C et al. Antithrombin III pretreatment reduces neutrophil recruitment into the lung and skeletal muscle tissues in the rat model of bilateral lower limb and reperfusion: A pilot study. Acta Anaesthesiol Scand 2005; 49: 1142-1148.

2. Turchányi B, Tóth B, Rácz I, Vendégh Z, Furész J, Hamar J. Ischemia reperfusion injury of skeletal muscle after selective deafferantation. Physiol Res 2005 54: 25-32.

3. Lin B, Ginsberg M, Busto R, Li L. Hyperglycemia triggers massive neutrophil deposition in brain following transient ischemia in rats. Neurosci Lett 2000; 278: $1-4$.

4. Homer-Vanniasinkam S, Crinnion JN, Gough MJ. Post-ischaemic organ dysfunction: a review. Eur J Vasc Endovasc Surg 1997; 14: 195-203.

5. Health Effects Institute 2001. Communication 9. Evaluation of Human Health Risk from Cerium Added to Diesel Fuel.

6. Colon J, Herrera L, Smith J, Patil S, Komanski C, Kupelian P et al. Protection from radiation-induced pneumonitis using cerium oxide nanoparticles. Nanomedicine 2009; 5: 225-231.
7. Niu J, Azfer A, Rogers LM, Wang X, Kolattukudy PE. Cardioprotective effects of cerium oxide nanoparticles in a transgenic murine model of cardiomyopathy. Cardiovasc Res 2007; 73: 549-559.

8. Wingard CJ, Walters DM, Cathey BL, Hilderbrand SC, Katwa W, Lin S et al. Mast cells contribute to altered vascular reactivity and ischemia reperfusion injury following cerium oxide nanoparticle instillation. Nanotoxicology 2011; 5: 531-545.

9. Estevez AY, Pritchard S, Harper K, Aston JW, Lynch A, Lucky JJ et al. Neuroprotective mechanisms of cerium oxide nanoparticles in a mouse hippocampal brain slice model of ischemia. Free Radic Biol Med 2011; 51: $1155-1163$.

10. Giri S, Karakoti A, Graham RP, Maguire JL, Reilly CM, Seal S et al. Nanoceria: a rare-earth nanoparticle as a novel anti-angiogenic therapeutic agent in ovarian cancer. PLoS One 2013; 8: e54578.

11. Manne ND, Arvapalli R, Nepal N, Shokuhfar T, Rice KM, Asano S et al. Cerium oxide nanoparticles attenuate acute kidney injury induced by intra-abdominal infection in Sprague-Dawley rats. J Nanobiotechnology 2015; 13: 75. doi: 10.1186/s12951-015-0135-z.

12. Rocca A, Moscato S, Ronca F, Nitti S, Mattoli V, Giorgi M et al. Pilot in vivo investigation of cerium oxide nanoparticles as a novel anti-obesity pharmaceutical formulation. Nanomedicine 2015; 11: 1725-1734.

13. Manne NDPK, Arvapalli R, Graffeo VA, Bandarupalli VVK, Shokuhfar T, Patel S et al. Prophylactic Treatment with Cerium Oxide Nanoparticles Attenuate Hepatic Ischemia Reperfusion Injury in Sprague Dawley Rats. Cell Physiol Biochem 2017; 42 (5): 1837-1846.

14. Gubernatorova EO, Liu X, Othman A, Muraoka WT, Koroleva EP, Andreescu $S$ et al. Europium-Doped Cerium Oxide Nanoparticles Limit Reactive Oxygen Species Formation and Ameliorate Intestinal Ischemia-Reperfusion Injury. Adv Healthc Mater 2017; 6 (14). doi: 10.1002/adhm. 201700176.

15. Montalvo-Jave EE, Escalante-Tattersfield T, Ortega-Salgado JA, Pina E, Geller DA: Factors in the pathophysiology of the liver ischemia-reperfusion injury. J Surg Res 2008; 147: 153-159.

16. Xu Z, Yu J, Wu J, Qi F, Wang H, Wang Z, Wang Z: The effects of two anesthetics, propofol and sevoflurane, on liver ischemia/reperfusion injury. Cell Physiol Biochem 2016; 38: 1631-1642.

17. Colon J, Hsieh N, Ferguson A, Kupelian P, Seal S, Jenkins DW et al. Cerium oxide nanoparticles protect gastrointestinal epithelium from radiationinduced damage by reduction of reactive oxygen species and upregulation of superoxide dismutase 2. Nanomedicine 2010; 6: 698-705.

18. Hirst SM, Karakoti A, Singh S, Self W, Tyler R, Seal S et al. Biodistribution and in vivo antioxidant effects of cerium oxide nanoparticles in mice. Environ Toxicol 2013; 28: 107-118.

19. Aalapati S, Ganapathy S, Manapuram S, Anumolu G, Prakya BM. Toxicity and bio-accumulation of inhaled cerium oxide nanoparticles in CD1 mice. Nanotoxicology 2014; 8: 786-798.

20. Yokel RA, Hussain S, Garantziotis S, Demokritou P, Castranova V, Cassee FR. The Yin: An adverse health perspective of nanoceria: uptake, distribution, accumulation, and mechanisms of its toxicity. Environ Sci Nano 2014; 1: 406-428.

21. Zinchuk VV. Erythrocyte deformability: physiological aspects. Usp Fiziol Nauk 2001; 32 (3): 66-78.

22. Kuypers FA. Red cell membrane damage. J Heart Valve Dis 1998; 7 : 387-395.

23. Sivilotti ML. Oxidant stres and haemolysis of the human erythrocyte. Toxicol Rev 2004; 23: 169-188.

24. Kotsuruba AV, Kopjak BS, Sagach VF, Spivak NJ. Nanocerium restores the erythrocytes stability to acid hemolysis by inhibition of oxygen and nitrogen reactive species in old rats. Fiziol ZH 2015; 61 (1): 3-9.

Received February 22, 2018. Accepted March 29, 2018. 